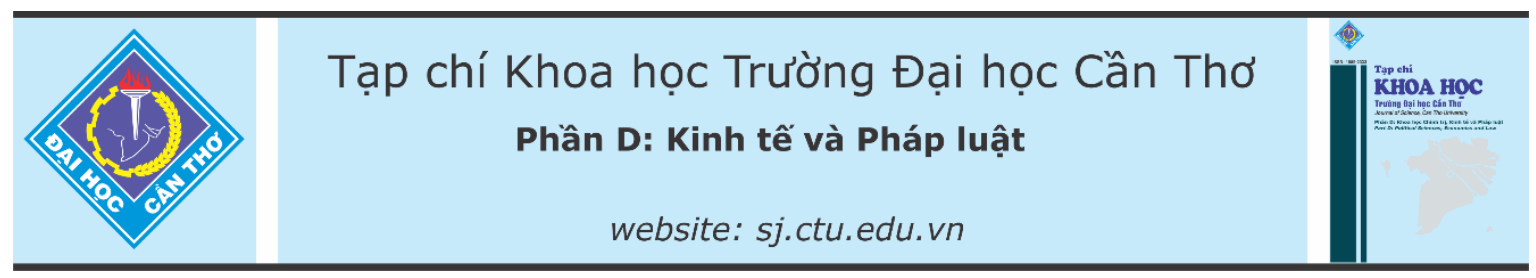

DOI:10.22144/ctu.jvn.2020.131

\title{
ĐO LƯờnG CHẤT LƯợNG DỊCH VỤ TIỀN GỦI TIẾT KIỆM CÁ NHÂN TẠI NGÂN HÀNG NÔNG NGHIỆP VÀ PHÁT TRIỂN NÔNG THÔN VIẸT NAM - MƯờI NĂM NHÌN LẠI
}

\author{
Hà Nam Khánh Giao ${ }^{1 *}$, Nguyễn Thị Cẩm Lệ ${ }^{2}$ và Bùi Nhất Vương ${ }^{3}$ \\ ${ }^{1}$ Khoa Vận tải Hàng không, Học viện Hàng không Việt Nam \\ ${ }^{2}$ Phòng Quản lý Đào tạo, Học viện Hàng không Việt Nam \\ ${ }^{3}$ Khoa Vận tải Hàng không, Học viện Hàng không Việt Nam \\ *Người chịu trách nhiệm về bài viết: Hà Nam Khánh Giao (email: khanhgiaohn@yahoo.com)
}

\section{Thông tin chung:}

Ngày nhận bài: $24 / 04 / 2020$

Ngày nhận bài sưa: $12 / 06 / 2020$

Ngày duyệt đăng: 28/10/2020

\section{Title:}

Measuring quality of personal savings deposit service at Vietnam Bank for Agriculture and Rural Development-a brief look after 10 years

\section{Tù khóa:}

10 năm nhìn lại, chất lượng dịch vu, Ngân hàng Nông nghiệp và Phát triển Nông thôn Viẹt Nam, phân tích chi tiêu, tiền gửi tiết kiệm cá nhân

\section{Keywords:}

A brief look after 10 years, dimension-to-dimension analysis, personal savings deposit, service quality, Vietnam Bank for Agriculture and Rural Development

\begin{abstract}
The research aims at comparing this research results to the same research which was conducted 10 years ago, by measuring the difference between the consumers rating perception and their rating expectation towards personal savings deposit at Vietnam Bank for Agriculture and Rural Development (Agribank), by using SERVQUAL scale dimension-by-dimension approach. The survey was conducted to 280 consumers who are using services at Agribank branches and transaction offices during the last quarter of 2019 towards service perception and service expectation, using the previous research results of Cronbach's Alpha and EFA, in which there are four main factors: reliability, interaction quality, service environment and price. The comparison results show that the dimensions of both perception and expextation changed positively over the last ten years. Concurrently this research also suggests some activities should-be-done activities to Agribank management to close the perception and expectation gaps, as well as approach and apply new banking applications in the era of open and integrated economy.
\end{abstract}

\section{TÓM TẮT}

Nghiên cứu nhằm so sánh kết quả nghiên cứu năm 2020 với kết quả của chính nghiên cưu tuơng tụ được thục hiện 10 năm truớc, trong đó có so sánh kỳ vọng và nhận thức của khách hàng về dịch vu tiền gửi tiết kiệm cá nhân tại Ngân hàng Nông nghiệp và Phát triển Nông thôn Việt Nam (Agribank), bằng cách sư dụng công cu nghiên cứu SERVQUAL, dưới dạng so sánh các chỉ tiêu và môt phần so sánh các biến số. Qua khảo sát 280 khách hàng đang giao dịch tại các chi nhánh và phòng giao dịch Agribank về kỳ vọng và nhận thức dịch vu trong quý 4 năm 2019, sủ dụng kết quả Cronbach's Alpha và EFA của nghiên cưu trước, việc phân tích cho thấy chất luợng dịch vu được đo lường qua mô hình hiệu chỉnh gồm 4 chi tiêu: độ tin cậy, chất luợng tương tác, môi trường dịch vu và giá cả. Kết quả so sánh có cho thấy nhũng chỉ tiêu đã thay đổi it nhiều trong vòng 10 năm qua, theo hướng tích cực hơn. Đồng thời, nghiên cứu này cũng đề xuất cho Ban quản lý Agribank một số việc nên làm nhằm ngày càng giảm khoảng cách kỳ vong - nhận thức của khách hàng, cũng nhu cập nhật liên tục những ứng dụng mới trong nền kinh tế mở, hội nhập.

Trích dẫn: Hà Nam Khánh Giao, Nguyễn Thị Cẩm Lệ và Bùi Nhất Vương, 2020. Đo lường chất lượng dịch vụ tiền gửi tiết kiệm cá nhân tại ngân hàng Nông nghiệp và Phát triển Nông thôn Việt Nam - Mười năm nhìn lại. Tạp chí Khoa học Trường Đại học Cần Thơ. 56(5D): 206-217. 


\section{GIỚI THIỆU}

Vấn đề đo lường chất lượng dịch vụ trong ngành ngân hàng ngày càng được coi trọng hơn khi ngành ngân hàng Việt Nam phát triển nhanh trong khoảng ba thập niên gần đây. Tiền gửi tiết kiệm là một trong những dịch vụ truyền thống tại ngân hàng. Các ngân hàng luôn nghiên cứu để tìm cách thu hút nguồn tiền gửi ổn định, chi phí thấp, thường từ các công ty và từ cá nhân. Trong số đó, nguồn cá nhân luôn được xem là ổn định nhất với một chi phí hợp lý.

Agribank được thành lập vào ngày 26 tháng 3 năm 1988 với tên gọi ban đầu là Ngân hàng Phát triển Nông nghiệp Việt Nam. Suốt hơn 30 năm hoạt động, Agribank luôn đứng đầu trong số các ngân hàng thương mại $(\mathrm{NHTM})$, và có vai trò nổi bật trong sự phát triển kinh tế quốc gia, đặc biệt trong khu vực nông nghiệp, nông thôn. Agribank đóng vai trò như người dẫn dắt thị trường, tuân thủ các chính sách của Đảng, Nhà nước, Chính phủ, và các chỉ thị của Nhân hàng Nhà nước Việt Nam về tiền tệ và vốn. Agribank là ngân hàng lớn nhất Việt Nam về nguồn vốn, tài sản, số nhân viên, hệ thống hoạt động và hệ thống khách hàng. Đến cuối năm 2019, Agribank có tổng số tài sản lên đến 1.452.181 tỷ đồng (so với trên 470.000 tỷ đồng cuối năm 2009), hơn 40.000 cán bộ công nhân viên (so với trên 35.000 cuối năm 2009), 2.300 văn phòng đại diện chi nhánh và phòng giao dịch (hầu như không thay đổi so với cuối năm 2009) (Ngô An, 2020; Minh Trung, 2020).

Năm 2019, Agribank là quán quân các Ngân hàng thương mại được vinh danh vị trí thứ 8 trong Bảng xếp hạng VNR500; được tổ chức xếp hạng tín nhiệm quốc tế Moody's công bố mức xếp hạng của Agribank tương đương mức tín nhiệm quốc gia và là mức xếp hạng cao nhất đối với các NHTM ở Việt Nam, top 20 trong Danh sách xếp hạng 1000 Doanh nghiệp nộp thuế thu nhập doanh nghiệp lớn nhất Việt Nam; giải thưởng Sao Khuê năm 2019; "Ngân hàng hỗ trợ đầu tư nông nghiệp công nghệ cao tiêu biểu", "Ngân hàng tiêu biểu vì cộng đồng". Năm 2019 là năm thứ tư liên tiếp Agribank đạt và vượt toàn bộ chỉ tiêu kinh doanh chủ yếu, hiệu quả kinh doanh tăng cao, thuộc nhóm doanh nghiệp nộp thuế cao nhất cả nước (Ngô An, 2020; Minh Trung, 2020).

Việc nghiên cứu liên tục chất lượng dịch vụ gửi tiền tiết kiệm cá nhân vẫn luôn là điều cần thiết qua thời gian. Đó chính là mục tiêu nhắm tới của nghiên cứu này, so sánh những tiến triển tốt, cũng như nhìn nhận sự thay đổi trong cách đánh giá của khách hàng theo thời gian, để có thể ngày một nâng cao chất lượng dịch vụ tiền gởi tiết kiệm cá nhân tại Agribank.

\section{TỔNG QUAN NGHIÊN CÚU}

\subsection{Chất lượng dịch vụ}

Cho đến nay, có rất nhiều nghiên cứu sâu về dịch vụ, các loại hình dịch vụ (Hà Nam Khánh Giao, Ao Thu Hoài và Pham Quang Vinh, 2019; Hà Nam Khánh Giao, 2004a, 2004b, 2017, 2019b), cũng theo đó, có rất nhiều định nghĩa về dịch vụ. Nghiên cứu này sử dụng khái niệm của Kotler and Amstrong (2001, p.291) "dịch vu là một hình thức sản phẩm bao gồm các hoạt động, các lợi ich, hay nhũng sư thỏa mãn dành để bán ra, về căn bản là vô hình, và không tạo nên tính sở hũu của bất kỳ điều gì”.

Có nhiều nghiên cứu khai thác các khía cạnh khác nhau về dịch vụ (Hà Nam Khánh Giao, 2011; Hà Nam Khánh Giao và Nguyễn Thu Hà, 2011; Hà Nam Khánh Giao và Huỳnh thị Phi Duyên 2016), trong đó một số nghiên cứu chú trọng đến chất lượng dịch vụ của nhiều ngành khác nhau (Hà Nam Khánh Giao và Lê Anh Phương, 2009; Hà Nam Khánh Giao và Huỳnh Bá Duy, 2010; Hà Nam Khánh Giao, 2018; Giao, 2018d; Giao et al., 2019), qua đó, có thể thấy chất lượng dịch vụ là một thành phần quan trọng trong nhận thức của khách hàng về dịch vụ. Khách hàng nhận thức dịch vụ dưới góc độ chất lượng và cách nó thỏa mãn họ theo như kinh nghiệm của họ. Theo đó, chất lượng dịch vụ có thể được định nghĩa như là nhận thức của khách hàng về một dịch vụ có thể bằng hoặc vượt kỳ vọng của họ bao nhiêu (Zeithaml and Bitner, 2000).

\section{2 Đo lường chất lượng dịch vụ ngân hàng}

Để đo lường chất lượng dịch vụ của các hoạt động ngân hàng, đã có rất nhiều mô hình chất lượng dịch vụ được đề xuất và vận dụng trong nhiều hoàn cảnh khác nhau. Trong nghiên cứu này, các khái niệm, lý thuyết được dùng có liên quan đến mô hình SERVQUAL (Parasuraman et al., 1988): Chất lượng dịch vụ (Service Quality) = Nhận thức khách hàng (Customers Perceptions-P) - Kỳ vọng khách hàng (Customers Expectation-E) hay viết ngắn gọn $\mathrm{Q}=\mathrm{P}-\mathrm{E}$. Các biến quan sát được sắp xếp trong 5 chỉ tiêu để khảo sát về nhận thức và kỳ vọng của khách hàng. Thang đo Likert 5 bậc được sử dụng, với 1 (hoàn toàn không đồng ý) đến 5 (hoàn toàn đồng ý). Kết quả được dùng để nhận diện các khoảng cách (gaps) trong nhận thức so với kỳ vọng của khách hàng về 5 chỉ tiêu đã được đề cập trên. Các khoảng cách của từng chỉ tiêu được tính toán như sau: 


$$
\mathrm{SQ}_{j}=\frac{\sum_{i=1}^{n j} P_{i j}-E_{i j}}{n j}
$$

Với SQj - Chất lượng dịch vụ về chỉ tiêu j, EijKỳ vọng về dịch vụ của công ty cho biến số $i$ trong chỉ tiêu j, Pij-Nhận thức về dịch vụ của công ty cho biến số $i$ trong chỉ tiêu $\mathrm{j}, \mathrm{nj}$ - Số biến số trong chỉ tiêu j.

Học hỏi từ những nhà nghiên cứu đi trước trong lĩnh vực ngân hàng, mô hình được dùng trong nghiên cứu này xuất phát từ mô hình SERVQUAL đã điều chỉnh còn 4 chỉ tiêu của Karatebe et al. (2005), và một chỉ tiêu khác về Giá cả (Price) do Joshua and Moli (2005), Joshua (2009) đề xuất: Chất lự̣ng dịch vụ tiền gưi tiết kiệm cá nhân tại Agribank $=$ f\{Môi truòng dịch vụ, Chất luộng tương tác, Độ thấu cảm, Độ tin cậy, Giá cả\}. Các biến quan sát trong từng chỉ tiêu được trình bày trong Bảng 2. Theo đó,

$H_{1}$ : Môi truờng dịch vu (Service environment- $S$ ) có tác động cùng chiều đến Chất lượng dịch vu tiền gửi tiết kiệm cá nhân tại Agribank

$\mathrm{H}_{2}$ : Chất luợng tuong tác (Interaction quality-I) có tác động cùng chiều đến Chất luợng dịch vu tiền gưi tiết kiệm cá nhân tại Agribank

$H_{3}$ : Độ thấu cảm (Empathy) có tác động cùng chiều đến Chất luợng dịch vu tiền gửi tiết kiệm cá nhân tai Agribank

$H_{4}$ : Độ tin cây (Reliability- R) có tác động cùng chiều đến Chất lượng dịch vu tiền gửi tiết kiệm cá nhân tại Agribank

H5: Giá cả hơp lý (Price-P) có tác động cùng chiều đến Chất lượng dịch vu tiền gưi tiết kiệm cá nhân tai Agribank

\section{PHƯƠNG PHÁP NGHIÊN CÚU}

Francis (1995) cho biết việc phân tích dữ liệu theo mô hình SERVQUAL có thể được thực hiện dưới nhiều dạng: phân tích biến số (item-by-item analysis), nghĩa là $\mathrm{P}_{1}-\mathrm{E}_{1}, \mathrm{P}_{2}-\mathrm{E}_{2}$; phân tích chỉ tiêu (dimension-by-dimension analysis) nghĩa là $\left(\mathrm{P}_{1}+\mathrm{P}_{2}\right.$ $\left.+P_{3}+P_{4}\right) / 4-\left(E_{1}+E_{2}+E_{3}+E_{4}\right) / 4$, trong đó $P_{1}$ đến $\mathrm{P}_{4}$, và $\mathrm{E}_{1}$ đến $\mathrm{E}_{4}$, đại diện cho các tuyên bố về nhận thức và kỳ vọng liên quan đến một chỉ tiêu; và tính chung một thang đo chất lượng dịch vụ $\left(\left(\mathrm{P}_{1}+\mathrm{P}_{2}+\right.\right.$ $\left.\left.\left.\mathrm{P}_{3}+\ldots .+\mathrm{P}_{28}\right) / 28\right)-\left(\mathrm{E}_{1}+\mathrm{E}_{2}+\mathrm{E}_{3}+\ldots .+\mathrm{E}_{28}\right) / \mathrm{n}\right)$, gọi là khoảng cách SERVQUAL. Nghiên cứu này áp dụng phân tích chỉ tiêu (dimension-by-dimension analysis), và một phần phân tích biến số (item-byitem analysis).

Việc hình thành thang đo chính thức thông qua quá trình khảo lược lý thuyết, và thực hiện phỏng vấn nhóm (focus group), thêm 3 cuộc phỏng vấn sâu với chuyên gia để điều chỉnh thang đo. Khi đã có bảng câu hỏi khảo sát chính thức, một cuộc khảo sát thử được tiến hành với mẫu nhỏ gồm 50 quan sát, phương pháp chọn mẫu thuận tiện, đối tượng khảo sát là những khách hàng đang giao dịch về tiền gửi cá nhân tại các chi nhánh và phòng giao dịch Agribank, chủ yếu trên địa bàn Thành phố Hồ Chí Minh (TPHCM). Việc khảo sát được thực hiện thông qua các giao dịch viên (teller) tại quầy, khi có khách hàng giao dịch tiền gửi cá nhân, giao dịch viên hỗ trợ việc yêu cầu khách hàng thực hiện trả lời bảng câu hỏi khảo sát sau khi giao dịch xong. Với kết quả nghiên cứu định lượng sơ bộ phù hợp cho nghiên cứu, việc khảo sát chính thức được thực hiện. Vẫn là phương pháp chọn mẫu thuận tiện, và đối tượng khảo sát nới rộng ra một số Phòng giao dịch tại Thủ Dầu Một (Bình Dương) và Biên Hòa (Đồng Nai) (so với chỉ TPHCM đầu năm 2010). Trong lần nghiên cứu đầu năm 2020, 300 bảng câu hỏi được phát ra (so với 200 đầu năm 2010), 280 câu trả lời sử dụng được (so với 162 đầu năm 2010), tỷ lệ 93,33\% (so với $81 \%$ đầu năm 2010). Việc phỏng vấn không lặp lại các đối tượng phỏng vấn ở năm 2010 và 2020 vẫn cho phép việc thực hiện so sánh kết quả nghiên cứu ở 2 thời điểm khác nhau, tương tự như việc thực hiện kiểm định $\mathrm{t}$ giữa 2 mẫu độc lập (Hà Nam Khánh Giao và Bùi Nhất Vương, 2019).

Sau khi nhập, làm sạch dữ liệu, tác giả thực hiện kiểm tra độ tin cậy của các thang đo bằng Cronbach's Alpha và phân tích nhân tố khám phá (exploratory factor analysis- EFA), và đều có được kết quả phù hợp. Bám sát mục tiêu nghiên cứu là so sánh các chỉ tiêu (dimension-to-dimention analysis), mà không tiến hành các kiểm định như trong các loại phương pháp nghiên cứu khác (Francis, 1996) với khái niệm thang đo hai nhóm kỳ vọng và nhận thức như đã chỉ ra trong SERVQUAL (Parasuraman et $a l ., 1988)$, kết quả EFA của nghiên cứu năm 2010 (Hà Nam Khánh Giao, 2010a) được sử dụng lại để thực hiện so sánh (Bảng 2). Theo đó, một hệ thống 19 biến quan sát trong các chỉ tiêu được so sánh theo kỳ vọng và nhận thức giữa 2 kết quả nghiên cứu năm 2010 và 2020 để tìm ra sự khác biệt, đồng thời cũng so sánh hệ thống các biến quan sát có giá trị trung bình (mean) cao nhất và thấp nhất để xem xét sự thay đổi trong suy nghĩ của khách hàng về chất lượng dịch vụ tiền gửi tiết kiệm cá nhân theo thời gian.

\section{KẾT QUẢ PHÂN TÍCH VÀ THẢO LUẬN}

\subsection{Mô tả mẫu}

Đặc trưng mẫu được trình bày trong Bảng 1 . Kích thước mẫu lớn hơn (280 so với 162), nhưng 
các cơ cấu trong thành phần mẫu của nghiên cứu này hầu như tương đồng với nghiên cứu trước của Hà Nam Khánh Giao (2010a).

\subsection{Xử lý dữ liệu}

Phân tích Cronbach's Alpha cho thấy tương quan biến- tổng của các biến đều lớn hơn 0,3 . Trong phân tích EFA, giá trị Eigen lớn hơn 1.0, độ giải thích lũy kế (cummulative \% of variance explained) lớn hơn $50 \%$, các biến phù hợp để phân tích xa hơn (Hà Nam Khánh Giao và Bùi Nhất Vương, 2019). Có thể thấy mô hình hiệu chỉnh trong Bảng 2.

\section{Bảng 1: Đặc trưng mẫu}

\begin{tabular}{|c|c|c|c|c|c|}
\hline \multirow{2}{*}{ Nhân tố } & \multirow{2}{*}{ Phân loại } & \multicolumn{2}{|c|}{2020} & \multicolumn{2}{|c|}{2010} \\
\hline & & Số lượng & Tỷ lệ & Số lượng & Tỷ lệ \\
\hline \multirow{3}{*}{ Tuổi } & Dưới 20 & 12 & 4,29 & 7 & 4,32 \\
\hline & Từ 20 đến dưới 50 & 220 & 78,57 & 129 & 79,63 \\
\hline & Từ 50 trở lên & 48 & 17,14 & 26 & 16,05 \\
\hline \multirow{2}{*}{ Giới } & Nam & 125 & 44,64 & 67 & 41,36 \\
\hline & Nữ & 155 & 55,36 & 95 & 58,64 \\
\hline \multirow{3}{*}{ Học vấn } & Trung học & 25 & 8,93 & 20 & 12,35 \\
\hline & Đại học & 225 & 80,36 & 121 & 74,69 \\
\hline & Sau đại học & 30 & 10,71 & 12 & 12,96 \\
\hline \multirow{5}{*}{ Nghề nghiệp } & Buôn bán nhỏ & 11 & 3,93 & 4 & 2,47 \\
\hline & Nhân viên & 199 & 71,07 & 109 & 67,28 \\
\hline & Giáo viên & 35 & 12,50 & 14 & 8,64 \\
\hline & Doanh nhân & 26 & 9,29 & 25 & 15,43 \\
\hline & Khác & 9 & 3,21 & 10 & 6,17 \\
\hline \multirow{4}{*}{$\begin{array}{l}\text { Gửi tiền tại } \\
\text { Agribank }\end{array}$} & Dưới 3 tháng & 78 & 27,86 & 51 & $\overline{31,48}$ \\
\hline & Từ 3 đến dưới 6 tháng & 6 & 2,14 & 7 & 4,32 \\
\hline & Từ 6 đến dưới 12 tháng & 13 & 4,64 & 27 & 16,67 \\
\hline & Từ 12 tháng trở lên & 183 & 65,36 & 77 & 47,53 \\
\hline
\end{tabular}

(Nguồn: kết quả khảo sát 280 bảng phỏng vấn năm 2020 và 162 bảng phỏng vấn năm 2010)

Bảng 2: Mô hình hiệu chỉnh

\begin{tabular}{|c|c|c|c|c|c|c|}
\hline \multicolumn{7}{|c|}{ Ma trận xoay } \\
\hline \multicolumn{3}{|c|}{ Các yếu tố } & \multicolumn{4}{|c|}{ Thành phần } \\
\hline$\underline{\mathbf{S T}}$ & T Mã & Biến số & 1 & $\mathbf{2}$ & $\mathbf{3}$ & \\
\hline 1 & $\mathrm{~S}_{8}$ & $\begin{array}{l}\text { Website: thân thiện, hiện đại, có đầy đủ thông tin cập nhật về lãi suất, đặc } \\
\text { biệt về hoạt động tiền gửi tiết kiệm }\end{array}$ & 0,834 & & & \\
\hline 2 & $\mathrm{R}_{2}$ & Nhân viên ngân hàng giữ bí mật các giao dịch của khách hàng & 0,769 & & & \\
\hline 3 & $\mathrm{~S}_{7}$ & $\begin{array}{l}\text { Phương tiện hiện đại trong giao dịch tiền gửi tiết kiệm (internet banking, } \\
\text { phone banking, ATM, ...) }\end{array}$ & 0,668 & & & \\
\hline 4 & $\mathrm{~S}_{5}$ & $\begin{array}{l}\text { Các vật dụng có liên quan đến hoạt động gửi tiền tiết kiệm (Sổ tiền gửi, } \\
\text { thẻ ATM, brochures, ...) }\end{array}$ & 0,661 & & & \\
\hline 5 & $\mathrm{R}_{3}$ & Nhân viên ngân hàng cung ứng thông tin chính xác cho khách hàng & 0,652 & & & \\
\hline 6 & $\mathrm{~S}_{6}$ & $\begin{array}{l}\text { Phương tiện hiện đại (máy in, máy photo, máy tính, quầy thâu ngân, } \\
\text { ATM,...) }\end{array}$ & 0,633 & & & \\
\hline 7 & $\mathrm{I}_{9}$ & Nhân viên ngân hàng đáp ứng nhanh chóng các yêu cầu của khách hàng & 0,561 & & & \\
\hline 8 & $\mathrm{I}_{1}$ & Nhân viên có đủ kiến thức chuyên môn để trả lời câu hỏi của khách hàng & 0,513 & & & \\
\hline 9 & $\mathrm{I}_{4}$ & Nhân viên ngân hàng có động thái truyền niềm tin cho khách hàng & & 0,865 & & \\
\hline 10 & $\mathrm{I}_{5}$ & $\begin{array}{l}\text { Nhân viên ngân hàng luôn lắng nghe một cách tôn trọng và cố hiểu khách } \\
\text { hàng }\end{array}$ & & 0,712 & & \\
\hline 11 & & Nhân viên ngân hảng có quan hệ tốt và than thiện với khách hàng & & 0,710 & & \\
\hline 12 & & Nhân viên luôn lịch thiệp với khách hàng & & 0,704 & & \\
\hline & $\mathrm{S}_{3}$ & Nội thất rộng rãi & & & & \\
\hline 14 & $\mathrm{~S}_{4}$ & Nhân viên và bàn làm việc luôn trong tình trạng gọn gàng & & & 703 & \\
\hline
\end{tabular}


Các yếu tố

STT Mã Biến số

$15 \mathrm{~S}_{1}$ Bề ngoài ngân hàng bắt mắt

$16 \mathrm{~S}_{2} \quad$ Phương tiện bắt mắt

$17 \mathrm{P}_{2} \quad$ Ngân hàng có chính sách linh hoạt cho những khoản rút trước hạn

$18 \mathrm{P}_{1} \quad$ Ngân hàng có lãi suất cạnh tranh

$19 \quad \mathrm{P}_{3} \quad$ Ngân hàng thu phí hợp lý

Giá trị Eigen

Tổng phuơng sai trich (\%)

Cronbach's Alpha

\section{Ma trận xoay}

Phuong pháp rút trich: Principal Component Analysis. Rotation Method: Varimax with Kaiser Normalization.

(Nguồn: kết quả phân tích 280 bảng phỏng vấn năm 2020 và 162bảng phỏng vấn năm 2010)

Bảng 3: Khoảng cách SERVQUAL

\begin{tabular}{|c|c|c|c|c|c|c|c|c|}
\hline \multirow{2}{*}{$\begin{array}{l}\text { Chỉ } \\
\text { tiêu }\end{array}$} & \multirow{2}{*}{ Mã } & \multirow{2}{*}{ Biến số } & \multicolumn{3}{|c|}{2020} & \multicolumn{3}{|c|}{2010} \\
\hline & & & $\mathbf{E}$ & $\mathbf{P}$ & $\mathbf{P}-\mathbf{E}$ & $\mathbf{E}$ & $\mathbf{P}$ & $\mathbf{P}-\mathbf{E}$ \\
\hline \multicolumn{3}{|c|}{ Độ tin cậy (Reliability) } & 4,60 & 4,17 & $-0,43$ & 4.46 & 3,94 & $-0,52$ \\
\hline & $\mathrm{S}_{8}$ & $\begin{array}{l}\text { Website: thân thiện, hiện đại, có đầy đủ } \\
\text { thông tin cập nhật về lãi suất, đặc biệt về } \\
\text { hoạt động tiền gựi tiết kiệm }\end{array}$ & 4,35 & 4,01 & $-0,34$ & 4,29 & 3,95 & $-0,34$ \\
\hline & $\mathrm{R}_{2}$ & $\begin{array}{l}\text { Nhân viên ngân hàng giữ bí mật các giao } \\
\text { dịch của khách hàng }\end{array}$ & 4,70 & 4,25 & $-0,45$ & 4,60 & 4,24 & $-0,36$ \\
\hline & $\mathrm{S}_{7}$ & $\begin{array}{l}\text { Phương tiện hiện đại trong giao dịch tiền gửi } \\
\text { tiết kiệm (internet banking, phone banking, } \\
\text { ATM,...) }\end{array}$ & 4,70 & 4,05 & $-0,65$ & 4,60 & 3,85 & $-0,75$ \\
\hline & $\mathrm{S}_{5}$ & $\begin{array}{l}\text { Các vật dụng có liên quan đến hoạt động gửi } \\
\text { tiền tiết kiệm (Sồ tiền gửi, thẻ ATM, } \\
\text { brochures, ..) }\end{array}$ & 4,55 & 4,43 & $-0,12$ & 4,23 & 3,86 & $-0,37$ \\
\hline & $\mathrm{R}_{3}$ & $\begin{array}{l}\text { Nhân viên ngân hàng cung ứng thông tin } \\
\text { chính xác cho khách hàng }\end{array}$ & 4,70 & 4,24 & $-0,36$ & 4,65 & 4,17 & $-0,39$ \\
\hline & $\mathrm{S}_{6}$ & $\begin{array}{l}\text { Phương tiện hiện đại (máy in, máy photo, } \\
\text { máy tính, quầy thâu ngân, ATM, ...) }\end{array}$ & 4,52 & 4,37 & $-0,15$ & 4,28 & 3,89 & $-0,39$ \\
\hline & $\mathrm{I}_{9}$ & $\begin{array}{l}\text { Nhân viên ngân hàng đáp ứng nhanh chóng } \\
\text { các yêu cầu của khách hàng }\end{array}$ & 4,55 & 3,98 & $-0,57$ & 4,41 & 3,72 & $-0,69$ \\
\hline & $\mathrm{I}_{1}$ & $\begin{array}{l}\text { Nhân viên có đủ kiến thức chuyên môn để } \\
\text { trả lời câu hỏi của khách hàng }\end{array}$ & 4,73 & 4,05 & $-0,68$ & 4,59 & 3,86 & $-0,73$ \\
\hline \multicolumn{3}{|c|}{ Chất lượng tương tác (Interaction quality) } & 4,52 & 3,88 & $-0,64$ & 4,45 & 3,73 & $-0,72$ \\
\hline & $\mathrm{I}_{4}$ & $\begin{array}{l}\text { Nhân viên ngân hàng có động thái truyền } \\
\text { niềm tin cho khách hàng }\end{array}$ & 4,64 & 3,92 & $-0,72$ & 4,47 & 3,73 & $-0,74$ \\
\hline & $\mathrm{I}_{5}$ & $\begin{array}{l}\text { Nhân viên ngân hàng luôn lắng nghe một } \\
\text { cách tôn trọng và cố hiểu khách hàng }\end{array}$ & 4,42 & 3,87 & $-0,55$ & 4,41 & 3,76 & $-0,65$ \\
\hline & $\mathrm{I}_{7}$ & $\begin{array}{l}\text { Nhân viên ngân hàng có quan hệ tốt và thân } \\
\text { thiện với khách hàng }\end{array}$ & 4,48 & 3,77 & $-0,71$ & 4,30 & 3,67 & $-0,63$ \\
\hline & $\mathrm{I}_{2}$ & Nhân viên luôn lịch thiệp với khách hàng & 4,54 & 3,95 & $-0,49$ & 4,62 & 3,75 & $-0,87$ \\
\hline \multicolumn{3}{|c|}{ Môi trường dịch vụ (Service environment) } & 4,23 & 3,92 & $-0,31$ & 4,13 & 3,62 & $-0,51$ \\
\hline & $\mathrm{S}_{3}$ & Nội thất rộng rãi & 4,23 & 3,78 & $-0,45$ & 4,13 & 3,62 & $-0,51$ \\
\hline & $\mathrm{S}_{4}$ & $\begin{array}{l}\text { Nhân viên và bàn làm việc luôn trong tình } \\
\text { trạng gọn gàng }\end{array}$ & 4,25 & 3,98 & $-0,27$ & 4,02 & 3,62 & $-0,40$ \\
\hline & $\mathrm{S}_{1}$ & Bề ngoài ngân hàng bắt mắt & 4,21 & 3,96 & $-0,25$ & 4,24 & 3,64 & $-0,60$ \\
\hline & $\mathrm{S}_{2}$ & Phương tiện bắt mắt & 4,20 & 3,95 & $-0,25$ & 4,12 & 3,59 & $-0,53$ \\
\hline \multicolumn{3}{|c|}{ Giá cả (Price) } & 4,13 & 4,16 & 0,03 & 4,12 & 4,15 & 0,03 \\
\hline
\end{tabular}




\begin{tabular}{|c|c|c|c|c|c|c|c|c|}
\hline \multirow{2}{*}{$\begin{array}{l}\text { Chỉ } \\
\text { tiêu }\end{array}$} & \multirow{2}{*}{ Mã } & \multirow{2}{*}{ Biến số } & \multicolumn{3}{|c|}{2020} & \multicolumn{3}{|c|}{2010} \\
\hline & & & $\mathbf{E}$ & $\mathbf{P}$ & $\mathbf{P}-\mathbf{E}$ & $\mathbf{E}$ & $\mathbf{P}$ & $\mathbf{P}-\mathbf{E}$ \\
\hline & $\mathrm{P}_{2}$ & $\begin{array}{l}\text { Ngân hàng có chính sách linh hoạt cho } \\
\text { những khoản rút trước hạn }\end{array}$ & 4,25 & 4,35 & 0,10 & 4,21 & 4,32 & 0,11 \\
\hline & $\mathrm{P}_{1}$ & Ngân hàng có lãi suất cạnh tranh & 4,40 & 4,40 & 0,00 & 4,37 & 4,44 & 0,07 \\
\hline & $\mathrm{P}_{3}$ & Ngân hàng thu phí hợp lý & 3,75 & 3,72 & $-0,03$ & 3,78 & 3,70 & $-0,08$ \\
\hline \multicolumn{3}{|c|}{ Điểm SERVQUAL } & 4,37 & 4,03 & $-0,34$ & 4,33 & 3,86 & $-0,47$ \\
\hline
\end{tabular}

(Nguồn: kết quả phân tích 280 bảng phỏng vấn năm 2020 và 162 bảng phỏng vấn năm 2010)

Sau khi hiệu chỉnh, có 4 chỉ tiêu đưa vào phân tích: Độ Tin cậy $(\mathrm{R})$ gồm 8 biến quan sát, Chất lượng tương tác (I) gồm 4 biến quan sát, Môi trường dịch vụ $(\mathrm{S})$ : gồm 4 biến quan sát, Giá cả $(\mathrm{P})$ : gồm 3 biến quan sát. Cả 4 chỉ tiêu này đều có Cronbach's Alpha khá cao, lần lượt là $0,890,0,819,0,709$ and 0,746, đảm bảo độ tin cậy (Hà Nam Khánh Giao, 2010a).

\subsection{Phân tích khoảng cách SERVQUAL}

Trong Bảng 3, điểm khoảng cách của từng biến số được tính bằng cách lấy điểm nhận thức (Perception- E) trừ điểm kỳ vọng (Expectation- E). Điểm khoảng cách dương (positive) cho thấy nhận thức đạt bằng hay vượt kỳ vọng, trong khi điểm khoảng cách âm (negative) cho biết thực tế dịch vụ còn chưa đạt đến kỳ vọng của khách hàng. Sau đó, điểm khoảng cách trung bình của từng chỉ tiêu (Di) được tính, và rồi điểm trung bình SERVQUAL (Av).

Vận dụng phân tích chỉ tiêu (dimension-bydimension analysis), có thể thấy rằng 3 tiêu chí Độ tin cậy $(\mathrm{R})$, Chất lượng tương tác $(\mathrm{I})$, Môi trường dịch vụ $(\mathrm{S})$ đều có khoảng cách $\mathrm{P}-\mathrm{E}$ âm, cho thấy thực tế dịch vụ còn chưa đạt đến kỳ vọng của khách hàng, chỉ có tiêu chí Giá cả (Price) có khoảng cách $\mathrm{P}-\mathrm{E}$ dương, cho thấy thực tế dịch vụ vượt kỳ vọng của khách hàng. Tất cả các chỉ số $E$ và $P$ năm 2020 đều cao hơn 2010, chứng tỏ khách hàng đã thay đổi nhiều, kỳ vọng cao hơn, và cũng nhận thức tốt nỗ lực của Agribank trong việc cải thiện chất lượng dịch vụ. Trong đó, khoảng cách lớn nhất là chất lượng tương tác (chỉ số $-0,64$ năm 2020 so với $-0,72$ năm 2010), cho biết rằng đây vẫn là chỉ tiêu được khách hàng đánh giá kém nhất về chất lượng dịch vụ tiền gửi tiết kiệm cá nhân tại Agribank trong vòng
10 năm qua, dù khoảng cách có giảm đi trong điều kiện cả kỳ vọng và nhận thức đều tăng, và đây vẫn sẽ là chỉ tiêu mà Agibank cần nghiên cứu lâu dài.

Trong khi đó, điều rất đáng tôn vinh Agribank là chỉ số $\mathrm{P}-\mathrm{E}$ cho Giá cả $(\mathrm{P})$ không thay đổi qua 10 năm $(0,03)$, dù vẫn là chỉ số dương rất nhỏ, cho thấy nhận thức đạt vượt kỳ vọng khách hàng. Chỉ số này cũng gợi mở một định hướng chi phí hợp lý, mang tính phục vụ cao, cũng chính là tầm nhìn và sứ mệnh của Agribank đặt ra và theo đuổi trong hơn 30 năm qua.

Ngoài ra, trong vòng 10 năm, Môi trường dịch vụ có khoảng cách $\mathrm{P}-\mathrm{E}$ giảm xuống đáng kể $(-0,31$ năm 2020 so với $-0,51$ năm 2010), điều này cho thấy Agribank đã chú trọng nhiều đến thành phần cơ sở vật chất (Tangibles) trong chất lượng dịch vụ theo Parasuraman et al. (1988). Tuy vậy, cũng phải nhìn nhận rằng, với sự phát triển nhanh chóng của ngành ngân hàng tại Việt Nam trong thòi gian vừa qua, tất cả các ngân hàng đều có định hướng cải thiện đáng kể môi trường dịch vụ, do vậy, khách hàng đã quen thuộc với đặc trưng này của toàn ngành, và có thể nói, đến năm 2020, nếu có một ngân hàng nào chưa đạt được một mức trang bị đáng quan tâm, chính ngân hàng đó sẽ chịu thiệt thòi, khi những cá nhân sẽ âm thầm rời bỏ ngân hàng.

Về tổng điểm SERVQUAL, có thể thấy rằng kỳ vọng không tăng nhiều (4,37 năm 2020 so với 4,33 năm 2010), trong khi nhận thức được đánh giá tốt hơn khá xa (4,03 năm 2020 so với 3,86 năm 2010), làm cho khoảng cách $\mathrm{P}-\mathrm{E}$ thu hẹp đáng kể (còn 0,34 năm 2020 so với $-0,47$ năm 2010), chứng tỏ khách hàng đánh giá ngày càng cao chất lượng dịch vụ tiền gửi tiết kiệm cá nhân tại Agribank. 
Bảng 4: Năm điểm khoảng cách nhỏ nhất

\begin{tabular}{|c|c|c|c|c|c|c|c|c|}
\hline \multirow{2}{*}{$\begin{array}{l}\text { Chỉ } \\
\text { tiêu }\end{array}$} & \multirow{2}{*}{ Mã } & \multirow{2}{*}{ Biến số } & \multicolumn{3}{|c|}{2020} & \multicolumn{3}{|c|}{2010} \\
\hline & & & $\mathbf{E}$ & $\mathbf{P}$ & $\mathbf{P}-\mathbf{E}$ & $\mathbf{E}$ & $\mathbf{P}$ & $\mathbf{P}-\mathbf{E}$ \\
\hline \multicolumn{3}{|c|}{ Độ tin cậy (Reliability) } & 4,60 & 4,17 & $-0,43$ & 4.46 & 3,94 & $-0,52$ \\
\hline & $\mathrm{S}_{8}$ & $\begin{array}{l}\text { Website: thân thiện, hiện đại, có đầy đủ } \\
\text { thông tin cập nhật về lãi suât, đặc biệt về } \\
\text { hoạt động tiền gửi tiết kiệm }\end{array}$ & & & & 4,29 & 3,95 & $-0,34$ \\
\hline & $\mathrm{R}_{2}$ & $\begin{array}{l}\text { Nhân viên ngân hàng giữ bí mật các giao } \\
\text { dịch của khách hàng }\end{array}$ & & & & 4,60 & 4,24 & $-0,36$ \\
\hline & $\mathrm{S}_{5}$ & $\begin{array}{l}\text { Các vật dụng có liên quan đến hoạt động gửi } \\
\text { tiền tiết kiệm (Sồ tiền gửi, thẻ ATM, } \\
\text { brochures, ...) }\end{array}$ & 4,55 & 4,43 & $-0,12$ & & & \\
\hline & $\mathrm{S}_{6}$ & $\begin{array}{l}\text { Phương tiện hiện đại (máy in, máy photo, } \\
\text { máy tính, quầy thâu ngân, ATM, ...) }\end{array}$ & 4,52 & 4,37 & $-0,15$ & & & \\
\hline Giá & Price) & & 4,13 & 4,16 & 0,03 & 4,12 & 4,15 & 0,03 \\
\hline & $\mathrm{P}_{2}$ & $\begin{array}{l}\text { Ngân hàng có chính sách linh hoạt cho } \\
\text { những khoản rút trước hạn }\end{array}$ & 4,25 & 4,35 & 0,10 & 4,21 & 4,32 & 0,11 \\
\hline & $P_{1}$ & gân hàng có lãi suất cạnh tranh & 4,40 & 4,40 & 0,00 & 4,37 & 4,44 & 0,07 \\
\hline & $\mathrm{P}_{3}$ & gân hàng thu phí hợp lý & 3,75 & 3,72 & $-0,03$ & 3,78 & 3,70 & $-0,08$ \\
\hline
\end{tabular}

(Nguồn: kết quả phân tích 280 bảng phỏng vấn năm 2020 và 162 bảng phỏng vấn năm 2010)

Vận dụng một phần phân tích biến số (item-byitem analysis), nghiên cứu sẽ phân tích 5 biến số có khoảng cách $\mathrm{P}-\mathrm{E}$ nhỏ nhất và biến số có khoảng cách $\mathrm{P}-\mathrm{E}$ lớn nhất có so sánh giữa hai nghiên cứu năm 2010 và năm 2020, để chỉ ra những biến quan sát nào Agribank cần chú ý nhất trong suốt hành trình cải thiện chất lượng chất lượng dịch vụ tiền gửi tiết kiệm cá nhân.

Trước hết, Bảng 4 cho thấy cả 3 biến quan sát của tiêu chí Giá cả vẫn giữ khoảng cách $\mathrm{P}-\mathrm{E}$ nhỏ nhất trong vòng 10 năm qua, làm cho toàn bộ tiêu chí đạt vượt kỳ vọng khách hàng. Agribank cần luôn giữ vững những biến số này trong thời gian tới. Hai biến số có khoảng cách $\mathrm{P}-\mathrm{E}$ còn lại đã có sự thay đổi qua 10 năm, nếu như năm 2010 là $S_{8}$ và $R_{2}$ thì đến năm 2020 đã là $S_{5}$ và $S_{6}$, điều đáng nói là mức giảm rất đáng quan tâm, trung bình 2 biến năm 2020 chỉ còn $-0,135$ so với trung bình 2 biến số năm 2010 là $-0,35$. Và cũng một điều đáng quan tâm ở đây, chính là việc 2 biến số đều thuộc tiêu chí Độ tin cậy, trong khi tiêu chí Độ tin cậy có khoảng $\mathrm{P}-\mathrm{E}$ khá lớn (-0,43 năm 2020 so với $-0,52$ năm 2010), đứng thứ hai về độ không đạt đến kỳ vọng khách hàng, như vậy, có thể thấy rằng những biến số còn lại trong tiêu chí Độ tin cậy tạo góp phần lớn trong việc tạo ra khoảng cách không đạt kỳ vọng lớn, Agribank cần cân nhắc điều này.

\section{Bảng 5: Năm điểm khoảng cách lớn nhất}

\begin{tabular}{|c|c|c|c|c|c|c|c|}
\hline \multirow{2}{*}{$\begin{array}{l}\text { Chỉ } \\
\text { tiêu }\end{array}$} & \multirow{2}{*}{ Mã Biến số } & \multicolumn{3}{|c|}{2020} & \multicolumn{3}{|c|}{2010} \\
\hline & & $\mathbf{E}$ & $\mathbf{P}$ & $P-E$ & $\mathbf{E}$ & $\mathbf{P}$ & $P-E$ \\
\hline \multicolumn{2}{|c|}{ Độ tin cậy (Reliability) } & 4,60 & 4,17 & $-0,43$ & 4.46 & 3,94 & $-0,52$ \\
\hline & $\begin{array}{ll}\mathrm{S}_{7} & \text { Phương tiện hiện đại trong giao dịch tiền gửi tiết } \\
\text { kiệm (internet banking, phone banking, ATM, ...) }\end{array}$ & 4,70 & 4,05 & $-0,65$ & 4,60 & 3,85 & $-0,75$ \\
\hline & $\begin{array}{l}\text { Nhân viên ngân hàng đáp ứng nhanh chóng các yêu } \\
\text { cầu của khách hàng }\end{array}$ & 4,55 & 3,98 & $-0,57$ & 4,41 & 3,72 & $-0,69$ \\
\hline & $\begin{array}{l}\text { Nhân viên có đủ kiến thức chuyên môn để trả lời } \\
\text { câu hỏi của khách hàng }\end{array}$ & 4,73 & 4,05 & $-0,68$ & 4,59 & 3,86 & $-0,73$ \\
\hline Chất & lượng tương tác (Interaction quality) & 4,52 & 3,88 & $-0,64$ & 4,45 & 3,73 & $-0,72$ \\
\hline & $\begin{array}{l}\text { Nhân viên ngân hàng có động thái truyền niềm tin } \\
\text { cho khách hàng }\end{array}$ & 4,64 & 3,92 & $-0,72$ & 4,47 & 3,73 & $-0,74$ \\
\hline & $\mathrm{I}_{5}$ Nhân viên luôn lịch thiệp với khách hàng & & & & 4,62 & 3,75 & $-0,87$ \\
\hline & $\begin{array}{l}\text { Nhân viên ngân hảng có quan hệ tốt và thân thiện } \\
\text { với khách hàng }\end{array}$ & 4,48 & 3,77 & $-0,71$ & & & \\
\hline
\end{tabular}

(Nguồn: kết quả phân tích 280 bảng phỏng vấn năm 2020 và 162 bảng phỏng vấn năm 2010) 
Bảng 5 cho thấy điểm khoảng cách lớn nhất ($0,87)$ năm 2010 là của biến số $I_{2}$ "Nhân viên luôn lịch thiệp với khách hàng" đã nhường chỗ cho $\mathrm{I}_{4}$ "Nhân viên ngân hàng có động thái truyền niềm tin cho khách hàng" về điểm $(-0,72)$ năm 2020 , và nhường vị trí trong top 5 điểm khoảng cách cao nhất cho $\mathrm{I}_{7}$ "Nhân viên ngân hảng có quan hệ tốt và thân thiện với khách hàng" với điểm $-0,71$ năm 2020 , đã gợi ý cho Agribank về việc xây dựng quan hệ khách hàng (Hà Nam Khánh Giao và Hoàng Trần Dung Hạnh, 2019). Về phía 03 biến số còn lại có khoảng cách điểm $\mathrm{P}-\mathrm{E}$ lớn, có thể khẳng định nhận định về các biến số còn lại trong chỉ tiêu Độ tin cậy chịu trách nhiệm chính trong việc làm cho điểm của chỉ tiêu này lớn, khi cả ba biến số $\mathrm{S}_{7}, \mathrm{I}_{9}, \mathrm{I}_{1}$ giữ nguyên vị trí trong nhóm 05 biến số có điểm khoảng cách âm lớn nhất, có thể thấy trang thiết bị cho hoạt động không giao dịch trực tiếp, cũng như kỹ năng, và kiến thức chuyên môn của nhân viên Agribank 10 năm qua đã có bước tiến, tuy nhiên, dưới cặp mắt khách hàng, có so sánh với các ngân hàng khác, vẫn còn là một ẩn số lớn, cần chú trọng cải thiện nhiều hơn nữa.

\section{HÀM Ý QUẢN TRI VÀ KẾT LUẬN}

\subsection{Hàm ý quản trị}

\subsubsection{Về chất luợng tuoong tác}

Chất lượng tương tác là chỉ tiêu có điểm khoảng cách lớn nhất, bao gồm 4 biến số cũng có điểm khoảng cách lớn, cả trong nghiên cứu năm 2020 lẫn trong nghiên cứu 2010. Trong chỉ tiêu này, tất cả các biến số đều liên quan đến kỹ năng mềm của nhân viên. Hơn nữa, từ kết quả khảo sát, ta có thể thấy kỳ vọng khách là rất cao. Để giải quyết tổng quát, Agribank nên cân nhắc việc huấn luyện nhân viên cả về kỹ năng mềm, kiến thức chuyên môn lẫn quy định, chính sách của Agribank. Việc huấn luyện cần được thực hiện cho cả nhân viên hiện tại và nhân viên mới (Hoàng Thị Anh Thư, 2017; Bạch Thị Mỹ Hương, 2018).

Đặc biệt, trong dịch vụ tiền gửi tiết kiệm cá nhân, khi các sản phẩm tiết kiệm mới được tung ra, tất cả nhân viên có liên quan cần được huấn luyện kỹ càng. Trong lĩnh vực đòi hỏi tính tương tác cao giữa người cung cấp dịch vụ và khách hàng, nếu khoảng cách này được thu hẹp, ngân hàng chắc chắn là người được hưởng lợi nhiều nhất. Khi nhân viên có kỹ năng giao tiếp tốt và chuyên môn vững, họ có thể cung cấp thông tin đủ và đúng đến khách hàng (Hoàng Thị Anh Thư, 2017; Bạch Thị Mỹ Hương, 2018).

Bên cạnh đó, cần xây dựng bản sắc văn hóa Agribank: "Trung thực, Kỷ cương, Sáng tạo, Chất lượng, Hiệu quả" (Hà Nam Khánh Giao, 2010b). Bản sắc vắn hóa này sẽ gắn kết tất cả các thành viên Agribank, biết cách nhìn nhận lẫn nhau đứng ở 2 đỉnh của tam giác dịch vụ, để ứng xử tốt nhất với khách hàng ở đỉnh còn lại (Hà Nam Khánh Giao, 2004a, 2004b). Ngoài ra, ý thức được việc tạo dựng mối quan hệ khách hàng hiện nay đang được các ngân hàng chú trọng và vận dụng, Agribank cũng cần có những nghiên cứu và định hướng theo mảng này thật tập trung (Hà Nam Khánh Giao và Hoàng Trần Dung Hạnh, 2019).

Một trong những phần thật sâu của chỉ tiêu này, ẩn đàng sau bề nổi của những số liệu, chính là mối tương quan công việc và gia đình, công việc và những hoạt động cá nhân khác của nhân viên ngân hàng, những tương quan này ảnh hưởng trực tiếp đến thái độ tương tác của nhân viên, và đã được nhiều nghiên cứu thực hiện (Hà Nam Khánh Giao và Lê Đăng Hoành, 2019; Hà Nam Khánh Giao và ctv., 2019; Giao et al., 2020), Agribank nên xem xét để cải thiện điều kiện làm việc trong nội bộ từng chi nhánh, phòng giao dịch, đặc biệt là nhân viên giao dịch tại quầy, những người trực tiếp tham gia vào dịch vụ tiền gửi tiết kiệm cá nhân.

Năm 2019, Agribank đạt giải thưởng "Ngân hàng vì cộng đồng", đây không chỉ là một vinh dự, mà sẽ còn là câu chuyện dài để Agribank tiếp tục phấn đấu. Một số nghiên cứu gần đây (Hà Nam Khánh Giao và Trịnh thị Hồng Tiên, 2017) cho thấy quan hệ chặt chẽ giữa Trách nhiệm xã hội doanh nghiệp (Corporate Social Responsibility- CSR) dến niềm tin của nhân viên ngân hàng, từ niềm tin về một ngân hàng phục vụ cộng đồng, sẽ giúp nhân viên, đặc biệt nhân viên giao dịch tại quầy, có động thái truyền niềm tin cho khách hàng, luôn lắng nghe một cách tôn trọng và cố hiểu khách hàng như 2 biến $\mathrm{I}_{4}, \mathrm{I}_{5}$ của chỉ tiêu chất lượng tương tác, trong đó $\mathrm{I}_{4}$ có khoảng cách $\mathrm{P}-\mathrm{E}$ lớn nhất theo nghiên cứu năm 2020 .

Về thị trường giao dịch tiền gửi khách hàng cá nhân, Agribank cũng có thể cần lưu ý đến những nhóm khách hàng khác nhau, có những nhu cầu khác nhau, để có thể xây dựng những chương trình khác nhau phù hợp với từng nhóm khách hàng (Hà Nam Khánh Giao và Hà Minh Đạt, 2014), từ đó cải thiện xa hơn chất lượng dịch vụ tiền gửi tiết kiệm cá nhân.

\subsubsection{Về độ tin cậy}

Tương tự, một phần của Độ Tin cậy cũng liên quan đến kỹ năng mềm, việc đào tạo huấn luyện nhân viên luôn nên được coi trọng tại Agribank. Ngoài ra, Agribank cũng cần cân nhắc cung cấp 
thông tin sẵn sàng cho những câu hỏi thường gặp qua website, các kênh thông tin nội bộ, ... sao cho bất kỳ khi nào cần, nhân viên có thể truy cập nhanh chóng và đáp ứng cho bất kỳ yêu cầu nào của khách hàng.

Giải pháp này cũng có thể hữu dụng cho khách hàng. Nếu những thông tin cần thiết luôn sẵn có, và dễ dàng truy cập đối với khách hàng, những yêu cầu của khách hàng đối với nhân viên Agribank sẽ giảm xuống, và độ thỏa mãn có thể tăng lên.

Các biến số $\mathrm{S}_{7}, \mathrm{I}_{9}, \mathrm{I}_{1}$ vẫn duy trì trong top 5 những biến số có khoảng cách $\mathrm{P}-\mathrm{E}$ lớn nhất từ nghiên cứu năm 2010 kéo dài đến nghiên cứu năm 2020, cho thấy các vấn đề này vẫn chưa được cải thiện đáng kể qua 10 năm. Ngày nay, khi lượng khách hàng dùng thẻ thanh toán tăng rất nhanh, việc chú trọng đến chất lượng dịch vụ thẻ thanh toán, có thể là ATM, thẻ ghi nợ (debit card), hay thẻ thanh toán (credit card) cả về cơ sở vật chất và dịch vụ mềm, liên kết với tài khoản cá nhân, sẽ là một điểm sáng cần chú ý đến trong việc nâng cao chất lượng dịch vụ ngân hàng (Giao, 2019; Hà Nam Khánh Giao, 2011, 2019a).

Bên cạnh đó, khi ngân hàng điện tử (bao gồm SMS banking, e-mobile banking, internet banking, liên kết các ví điện tử) được sử dụng ngày càng nhiều hơn, và đa dạng hơn, được nhiều nghiên cứu chú trọng phần vận dụng (Hà Nam Khánh Giao và Phạm thị Ngọc Tú, 2010; Hà Nam Khánh Giao và Võ văn Linh, 2015), Agribank cần chú trọng nâng cao hơn nữa những tiện ích dịch vụ này, như để thanh toán mua hàng (Giao and Mo, 2018; Giao et al., 2018a; Giao et al., 2018b; Giao, 2018a, 2018c, 2018f, 2018g; Vuong and Giao, 2019; Giao et al, 2019, Giao, 2020), thanh toán học phí các loại (Giao and Hoa, 2018; Giao and Lien, 2018; Giao, 2018e), hay thanh các loại vé máy bay, du lịch (Giao and Son, 2018; Giao et al., 2018c; Giao, 2018b; Hà Nam Khánh Giao và Đặng thị Nga, 2018), hay rất nhiều những mảng thanh toán khác. Khách hàng thậm chí có thể quan tâm đến những ứng dụng xa hơn nữa, ví dụ như sự kết nối những tài khoản cá nhân của họ ở các ngân hàng khác nhau, có thể là tài khoản thanh toán hay tài khoản tiền gửi, để có thể linh động sử dụng nguồn tiền của họ trong rất nhiều những nhu cầu khác nhau, thông qua ngân hàng điện tử, mà không phải quá lo lắng về tính bảo mật, cũng như tính an toàn của các tài khoản, đó cũng là điều Agribank cần nghiên cứu xa hơn, để nâng cao hơn nữa chất lượng dịch vụ ngân hàng cá nhân nói chung, và chất lượng dịch vụ tiền gửi tiết kiệm cá nhân nói riêng.

\subsubsection{Về môi truờng dịch vu}

Môi trường dịch vụ là một trong 3 chỉ tiêu có điểm khoảng cách âm. Nhằm thu hẹp khoảng cách này, các phương tiện hữu hình bao gồm nội thất, bề ngoài ngân hàng, và cả các phương tiện làm việc như quầy giao dịch, trang phục nhân viên cần được cân nhắc them. Khu vực giao dịch vẫn còn được đánh giá chật hẹp, Agribank có thể cân nhắc việc mở rộng khu vực giao dịch, hay thiết kế lại khu vực cho thấy có nhiều khoảng không hơn.

Bề ngoài của ngân hàng từ các chi nhánh đến phòng giao dịch, cần được chú trọng theo hướng vừa bảo đảm tính dễ nhận diện, thống nhất trong toàn hệ thống, và tạo vẻ thu hút đối với đa số cá nhân có thể là khách hàng tiềm năng của ngân hàng. Các phương tiện khác như website (phần tiền gửi cá nhân), sổ tiết kiệm, brochures, tờ rơi... cũng có thể cần cân nhắc, để tạo tính thu hút cao hơn. Tính thu hút ở đây không chỉ là tính bắt mắt, mà còn là tính dễ hiểu, dễ đọc, dễ điền, dễ nhận diện đâu là nơi người dùng cần thiết nhất.

Ngoài ra, nghiên cứu 2020 còn cho thấy khách hàng hiện nay, đặc biệt trong thời gian đại dịch Covid-19, môi trường dịch vụ internet banking cần được chú trọng, sao cho các ứng dụng dễ tài, dễ nhìn, dễ nhận diện, dễ sử dụng, và tiện dụng trong không gian mạng. Điều Agribank có thể lưu ý điều chỉnh là việc còn lệ thuộc vào nhà mạng Viettel trong một số dịch vụ, đặc biệt là dịch vụ Apay, sẽ làm giàm tính hấp dẫn cho môi trường dịch vụ Agribank.

\subsubsection{Về giá cả}

Khoảng cách $\mathrm{P}-\mathrm{E}$ cho chỉ tiêu giá cả là 0,03 trong cả 2 cuộc nghiên cứu năm 2010 và 2020 cho thấy lãi suất và phí dịch vụ tiền gửi tiết kiệm cá nhân của Agribank là vượt kỳ vọng khách hàng trong suốt 10 năm qua. Đây là điểm mạnh rất lớn khi Agribank đang đi đúng hướng chiến lược đề ra trong tầm nhìn phát triển theo hướng ngân hàng hiện đại "tăng trưởng - an toàn - hiệu quả - bền vững”, định vị hình ảnh, thương hiệu Agribank - Ngân hàng vì "tam nông" - Ngân hàng bán lẻ - Ngân hàng vì cộng đồng.

Thành công trong chỉ tiêu này của Agribank chính là từ việc hình thành những chính sách về khung lãi suất hợp lý, trong đó có lãi suất bậc thang, cũng như việc hình thành những chính sách cho rút trước hạn, cho vay trên tài khoản tiền gửi với mức lãi suất hợp lý, điều này cũng thể hiện kiến thức nghề nghiệp cao, cùng với khả năng ứng dụng hợp lý của các thành phần hoạch định chính sách của 
Agribank, định hình nên loại hình chất lượng có thể cảm nhận được từ phía khách hàng.

\subsection{Kết luận}

Nghiên cứu này vận dụng lý thuyết về mô hình SERVQUAL để đo lường chất lượng dịch vụ gửi tiền tiết kiệm cá nhân tại Agribank. Mô hình giúp các nhà quản lý Agribank hiểu thêm về khách hàng, hiểu những kỳ vọng của họ cũng như ý kiến đánh giá của họ về chất lượng dịch vụ ngân hàng. Qua đó, Agribank có thể hình dung phần nào ngân hàng đang ở đâu và cần làm những gì để tiếp cận kỳ vọng của khách hàng về dịch vụ.

Trong bối cảnh của nghiên cứu, cả kỳ vọng lẫn nhận thức của khách hàng được tóm tắt bằng 4 chỉ tiêu: Độ Tin cậy, Chất lượng Tương tác, Môi trường Dịch vụ, Giá cả, và cơ sở tính khoảng cách $\mathrm{P}-\mathrm{E}$ chính là cơ sở để đánh giá chất lượng dịch vụ tiền gửi tiết kiệm cá nhân qua 2 mốc thời gian 2010 và 2020. Điều đặc biệt của nghiên cứu là chỉ tiêu Giá cả có điểm khoảng cách dương ổn định 0,03 qua 2 nghiên cứu năm 2010 và 2020 , trong khi 3 chỉ tiêu còn lại có điểm khoảng cách âm qua 2 nghiên cứu năm 2010 và 2020 . Điều này cho thấy lãi suất và phí của Agribank vượt kỳ vọng khách hàng, trong khi các chỉ tiêu khác cần được chú ý thu hẹp khoảng cách.

Từ đó, nghiên cứu đã đưa ra 4 đề xuất hàm ý quản trị chính về 4 chỉ tiêu, có thể cùng Agribank thu hẹp các khỏang cách, cũng chính là nhằm nâng cao chất lượng dịch vụ tiền gửi cá nhân tại Agribank.

\subsection{Những hạn chế và đề xuất hướng nghiên cứu xa hơn}

Nghiên cứu đã thực hiện được mục tiêu so sánh kết quả năm 2020 với kết quả năm 2010, tuy vậy vẫn còn một số hạn chế: (1) khung so sánh dựa vào kết quả của năm 2010, với chỉ 19 biến quan sát trong 4 chỉ tiêu, làm cho một số biến quan sát theo kết quả năm 2020, từ sự phát triển của dịch vụ ngân hàng, không được sử dụng trong nghiên cứu này, (2) phương pháp lấy mẫu thuận tiện, phạm vi nghiên cứu giới hạn tại TPHCM, Bình Dương Đồng Nai, chưa cho phép có độ khái quát hóa cao, (3) phương pháp phân tích so sánh chỉ tiêu và một phần so sánh biến số được sử dụng trong nghiên cứu này có thể chưa thấy tính phổ quát tác động đồng thời của các chỉ tiêu đến chất lượng dịch vụ tiền gửi tiết kiệm cá nhân ra sao. Đó cũng là những gợi ý cho các hướng nghiên cứu tiếp theo.

\section{TÀI LIỆU THAM KHẢO}

Bạch Thị Mỹ Hương. 2018. Nghiên cứu các nhân tố ảnh hưởng đến quyết định gửi tiền tiết kiệm của khách hàng cá nhân tại Ngân hàng Thương mại cổ phần Công Thương Việt Nam, chi nhánh Huế. Luận văn Cao học. Trường Đại học Kinh tế Huế, Đại học Huế. Thành phố Huế.

Francis, A.B., 1996. SERVQUAL: Review, Critique, Research agenda. European Journal of Marketing, 30(1): 8-32. DOI: 10.1108/03090569610105762

Giao, H.N.K. and Hoa, D.T.T., 2018. Factors affect the learning motivation at Khoa Tri English Center (KTEC). Global and Stochastic Analysis. 5(6): 329-337. DOI: 10.31219/osf.io/ufb4w.

Giao, H.N.K. and Lien, L.T.P., 2018. The factors effect the English training at the Foreign languages - Informatics Center, University of Banking, HoChiMinh City, Vietnam. Global and Stochastic Analysis, 5(6), Special Issue: 340352. DOI: 10.31219/osf.io/rnuad.

Giao, H.N.K. and Mo, N.T.H., 2018. Factors influencing consumers' impulse television buying decision at Best Buy Vietnam (BBVN), 5(6), Special Issue: 353-369. DOI: 10.31219/osf.io/cgz2x

Giao, H.N.K. and Phuong, L.A., 2010. Measuring the Service Quality at Binh Phuoc Hospital- a dimension-by-dimension approach. Journal of Sciences and Technology Development, 13(1): 31-43. DOI: 10.31219/osf.io/us64m

Giao, H.N.K. and Son, L.T., 2018. MICE tourism development- Examination from the supply side in Dalat City, Vietnam. Global and Stochastic Analysis, 5(6), Special Issue: 371-390. DOI: 10.31219/osf.io/r36yf.

Giao, H.N.K., 2018a. Decision to choose fast food restaurants of the young people in HCMC, Vietnam. National Academy of Managerial Staff of Culture and Arts Herald, 4: 471-485. http://jrhnamsca.icu/index.php/hnamsca/issue/vie w/1. DOI: 10.31219/osf.io/xgv2k.

Giao, H.N.K., 2018b. Decision to purchase online airline tickets in Ho Chi Minh City, Vietnam. National Academy of Managerial Staff of Culture and Arts Herald, 2018b, 4: 459-470. http://jrhnamsca.icu/index.php/hnamsca/issue/vie w/1. DOI: 10.31219/osf.io/fzh5v.

Giao, H.N.K., 2018c. Factors Influencing Customer Behavior of Butter Oil Substitute in Vietnam. Journal of Business and Economics, 9(3): 266274. DOI: $10.15341 /$ jbe $(2155$ 7950)/03.09.2018/005. DOI: 10.31219/osf.io/gn6em

Giao, H.N.K., 2018d. Measuring service quality in construction project management service at AIC Management Co., Ltd.- A dimension-bydimension analysis. International Journal of Applied Business and Economic Research, 16(1): 165-175. DOI: 10.31219/osf.io/bf5ke. 
Giao, H.N.K., 2018e. Satisfaction and word-ofmouth at the language centers in Vietnam. International Journal of Applied Business and Economic Research, 16(2): 427-433. DOI: 10.31219/osf.io/etvjd.

Giao, H.N.K., 2018f. The influence of Country of Origin Image on HCMC consumer attitudes towards Vietnamese garments. International Journal of Applied Business and Economic Research, 16(2): 435-443. DOI: $10.31219 /$ osf.io/wr9sq.

Giao, H.N.K., 2018g. Vietnamese consumers' attitude on television advertisement of skin care. National Academy of Managerial Staff of Culture and Arts Herald, 4: 486-491. http://jrhnamsca.icu/index.php/hnamsca/issue/vie w/1. DOI: 10.31219/osf.io/a2bn9.

Giao, H.N.K., 2019. Customer Satisfaction towards ATM Services: A Case of Vietcombank Vinh Long, Vietnam. Journal of Asian Finance, Economics and Business, 6(1): 141-148. DOI: 10.13106/jafeb.2019.vol6.no1.141.

Giao, H.N.K., 2020. Customer Satisfaction at Tiki.vn E-Commerce Platform. Journal of Asian Finance, Economics and Business, 7(4): 173-183. DOI:https://doi.org/10.13106/jafeb.2020.vol7.no 4.173

Giao, H.N.K., Duong, P.N. and Tu, T.N., 2018a. Research on Consumer Behavior of Wine in HoChiMinh City. Global and Stochastic Analysis, 5(8), Special Issue: 111-122. DOI: 10.31219/osf.io/4cvn7.

Giao, H.N.K., Hoang, C.C. and Vinh, P.Q., 2018 b. Factor affecting buying decision of Amalie lubricants in Vietnam. Global and Stochastic Analysis, 5(8) Special Issue: 137-150. DOI: 10.31219/osf.io/kgc56.

Giao, H.N.K., Kiem, D., Son, L.T. and Dung, T.Q. 2018c. Satisfaction of tourists to Hoi An ancient town, Vietnam,. 2018; 5(8), Special Issue: 123136. DOI:10.31219/osf.io/sbjev.

Giao, H.N.K., Trung, B. and Truong, P.Q., 2019. Outbound service quality at Wan Hai Lines. Journal of Asian Finance, Economics and Business, 6(1): 177-185. doi:10.13106/jafeb.2019.vol6.no1.175

Giao, H.N.K., Vuong, B.N. and Quan, T.N., 2019. The influence of website quality on consumer's e-loyalty through the mediating role of e-trust, esatisfaction, and perceived enjoyment: An evidence from online shopping in Vietnam. Uncertain Supply Chain Management, 8(2): 351370. DOI: 10.5267/j.uscm.2019.11.004.

Giao, H.N.K., Vuong, B.N., Huan, D.D., Tushar, H. and Quan, T.N., 2020. The Effect of Emotional Intelligence on Turnover Intention and the Moderating Role of Perceived Organizational
Support: Evidence from the Banking Industry of Vietnam. Sustainability. MDPI, 12(5): 18571882. doi:10.3390/su12051857.

Hà Nam Khánh Giao, 2004a. Marketing Dịch vụMô hình 5 Khoảng cách Chất lượng Dịch vụ. Nhà Xuất bản Thống kê.

Hà Nam Khánh Giao, 2004b. Marketing Dịch vụPhục vụ Khách hàng tốt hơn. Nhà Xuất bản Thống kê.

Hà Nam Khánh Giao, 2010a. Đo lường chất lượng dịch vụ tiền gửi tiết kiệm tại Agribank. Tạp chí Ngân hàng, 20: 21-28. DOI:

10.31219/osf.io/afskm

Hà Nam Khánh Giao 2010b. Mạn đàm thước đo Văn hóa Doanh nghiệp trong các Ngân hàng thương mại. Tạp chí Ngân hàng, 22: 25-27.

Hà Nam Khánh Giao, 2011. Mức độ hài lòng của khách hàng sử dụng thẻ thanh toán tại TPHCM. Tạp chí Khoa học Đào tạo Ngân hàng, 111: 2430. DOI: $10.31219 /$ osf.io/83fgr

Hà Nam Khánh Giao, 2017. Giáo trình Cao học Quản trị Kinh doanh Quốc tế. Nhà xuất bản Kinh tế TPHCM. DOI: 10.31219/osf.io/94dnx. ISBN: 978-604-922-474-4

Hà Nam Khánh Giao, 2018. Sách chuyên khảo Đo lường chất lượng dịch vụ tại Việt Nam- nhìn từ góc độ khách hàng. Nhà xuất bản Tài chính. Hà Nội. DOI: 10.31219/osf.io/cqh68. ISBN: 978604-79-1788-4

Hà Nam Khánh Giao, 2019a. Giáo trình Cao học Quản trị Hệ thống Thông tin- Từ Góc nhìn Kinh doanh. Nhà xuất bản Tài chính. Hà Nội. DOI: 10.31219/osf.io/uxyw3. ISBN: 978-604-792129-4

Hà Nam Khánh Giao, 2019b. Sách chuyên khảo Tránh và Khắc phục sai sót trong thực hiện luận văn Kinh doanh và Quản lý tại Việt Nam. Nhà xuất bản Tài chính. Hà Nội. DOI: 10.31219/osf.io/p6bzf. ISBN: 978-604-79-2011-2

Hà Nam Khánh Giao and Huỳnh Bá Duy, 2009. Service Quality of outsourcing at Quantic Co., Ltd- a dimension-by dimension approach. Journal of Sciences and Technology Development, 12: 56-70. DOI: 10.31219/osf.io/n8r73

Hà Nam Khánh Giao và Bùi Nhất Vương, 2019. Giáo trình Cao học Phương pháp Nghiên cứu Khoa học trong Kinh doanh- Cập nhật SmartPLS. Nhà xuất bản Tài chính. Hà Nội. DOI: 10.31219/osf.io/hbj3k. ISBN: 978-604-79-2154-6

Hà Nam Khánh Giao và Đặng thị Nga, 2018. Ý định mua vé máy bay qua đại lý của người tiêu dùng TPHCM. Tạp chí Công Thương, 14, tháng 112018, 317-324. DOI: 10.31219/osf.io/swe3r.

Hà Nam Khánh Giao và Hà Minh Đạt, 2014. Sự khác biệt giữa các nhóm người cao tuổi trong việc đánh 
giá các yếu tố lựa chọn ngân hàng tại TPHCM. Tạp chí Phát triển Kinh tể, 280: 97-115.

Hà Nam Khánh Giao và Hoàng Trần Dung Hạnh. 2019. Chất lượng mối quan hệ giữa khách hàng cá nhân và Ngân hàng TMCP Đại Chúng Việt Nam (PVcomBank) chi nhánh Sài gòn. Tạp chí Công Thương, 1: 106-113. DOI:

10.31219/osf.io/vrmj4.

Hà Nam Khánh Giao và Huỳnh thị Phi Duyên, 2016. Các yếu tố ảnh hưởng đến năng lực cạnh tranh của Agribank chi nhánh Quảng Ngãi. Tạp chí Công nghệ Ngân hàng, 125: 55-64. DOI: 10.31219/osf.io/5hj7v.

Hà Nam Khánh Giao và Lê Đăng Hoành, 2019. Động lực làm việc của nhân viên tại ngân hàng TMCP Đầu tư và Phát triển Việt Nam, Chi nhánh Đông Sài Gòn. Tạp chí Công Thương, 1: 321327. DOI: $10.31219 /$ osf.io/qmgwx.

Hà Nam Khánh Giao và Nguyễn thị Thu Hà, 2011. Tác động của chính sách cho vay của ngân hàng đến khách hàng mua nhà Phú Mỹ Hưng. Tạp chí Ngân hàng, 6: 25-29. DOI:

10.31219/osf.io/rvmuq

Hà Nam Khánh Giao và Phạm thị Ngọc Tú, 2010. Đánh giá Chất lượng dịch vụ Ngân hàng điện tử tại Việt Nam. Tạp chí Ngân hàng, 18: 20-28. DOI: 10.31219/osf.io/tr6k4

Hà Nam Khánh Giao và Trịnh Thị Hồng Tiên, 2017. Ảnh hưởng của CSR đến niềm tin của nhân viên ngân hàng TMCP tại TP Sóc Trăng. Tạp chí Ngân hàng, 9: 33-38. DOI: 10.31219/osf.io/weq28

Hà Nam Khánh Giao và Võ văn Linh, 2015. Các yếu tố ảnh hưởng đến sự chấp nhận sử dụng dịch vụ ngân hàng điện tử tại tỉnh Quảng Ngãi. Tạp chí Ngân hàng, 22: 32-38. DOI: 10.31219/osf.io/e35c8.

Hà Nam Khánh Giao, Ao Thu Hoài và Phạm Quang Vinh, 2019. Quản trị Kinh doanh Dịch vụ- Từ Góc nhìn Marketing. Nhà xuất bản Truyền thông Thông tin Hà Nội. DOI: 10.31219/osf.io/98hrd. ISBN: 978-604-80-3905-9

Hà Nam Khánh Giao, Lâm Thu Huyền và Phạm Hữu Hà, 2019. Về động lực làm việc của nhân viên Eximbank Chi nhánh Cộng Hòa. Tạp chí Công Thương, 20: 334-340. DOI:

10.31219/osf.io/z8jak.

Hoàng Thị Anh Thư, 2017. Nghiên cứu các nhân tố ảnh hưởng đến quyết định lựa chọn ngân hàng gửi tiết kiệm của khách hàng cá nhân tại Huế.
Tạp chí Phát triển Khoa học và Công nghệ, 20: 96-104

Joshua, A.J. and Moli, P.K., 2005. Expectations and Perceptions of Service Quality in Old and New Generation Banks - a Study of Select Banks in the South Canada Region. Indian Journal of Marketing, 37(3): 18.

Joshua, A.J., 2009. Adoption of technology-enabled banking self-services: antecedents and consequences. Doctoral Thesis. School of Management Studies, Cochin University of Science and Technology.

Karatebe, O.M., Yavas, U. and Babakus, E., 2005. Measuring Service Quality of Banks: Scale Development and Validation. Journal of Retailing and Consumer Services, 12: 373-383.

Kotler, P. and Amstrong, A., 2001. Principles of Marketing. ( $9^{\text {th }}$ edition). Prentice Hall International Inc.

Minh Trung. 2020. Đảng ủy Agribank tổng kết công tác năm 2019 triển khai nhiệm vụ năm 2020. Ngày truy cập 20/02/2020. Địa chỉ https://www.agribank.com.vn/vn/veagribank/tin-tuc-su-kien/cac-tin-khac/dang-boagribank/dang-uy-agribank-tong-ket-cong-tacnam-2019-trien-khai-nhiem-vu-nam-2020

Ngô An, 2020. Năm 2019 Agribank đạt nhiều giải thưởng uy tín. Ngày truy cập 20/02/2020. Địa chỉ https://www.agribank.com.vn/vn/veagribank/tin-tuc-su-kien/tin-ve-agribank/hoatdong-agribank/nam-2019-agribank-dat-nhieugiai-thuong-uy-tin

Parasuraman, A., Zeithaml, V.A. and Berry, L.L., 1988. SERVQUAL: a Multiple Item Scale for Measuring Customer Perceptions of Service Quality, Journal of Retailing, 64(1): 12-40.

Vuong, B.N. and Giao, H.N.K., 2019. The impact of brand globalness on consumers purchase intention and the moderating role of consumer ethnocentrism an evidence from Vietnam. Journal of International Marketing, 32(1): 47-68. DOI: 10.1080/08961530.2019.1619115.

Zeithaml, V.A., Berry, L.L. and Parasuraman, A., 1988. Communication and Control Processes in the Delivery of Service Quality. Journal of Marketing, 52: 35-48.

Zeithaml, V.A. and Bitner, M.J., 2000. Services Marketing: Integrating Customer Focus across the Firm. Irwin McGraw-Hill. 